\title{
CUATRO REFLEXIONES SOBRE EL ACTO PEDAGÓGICO
}

\author{
Por: Liberio Salazar Trujillo*
}

"En el desarrollo cultural del niño, toda función aparece dos veces:

primero a nivel social y más tarde a nivel individual».

\section{VYGOTSKY}

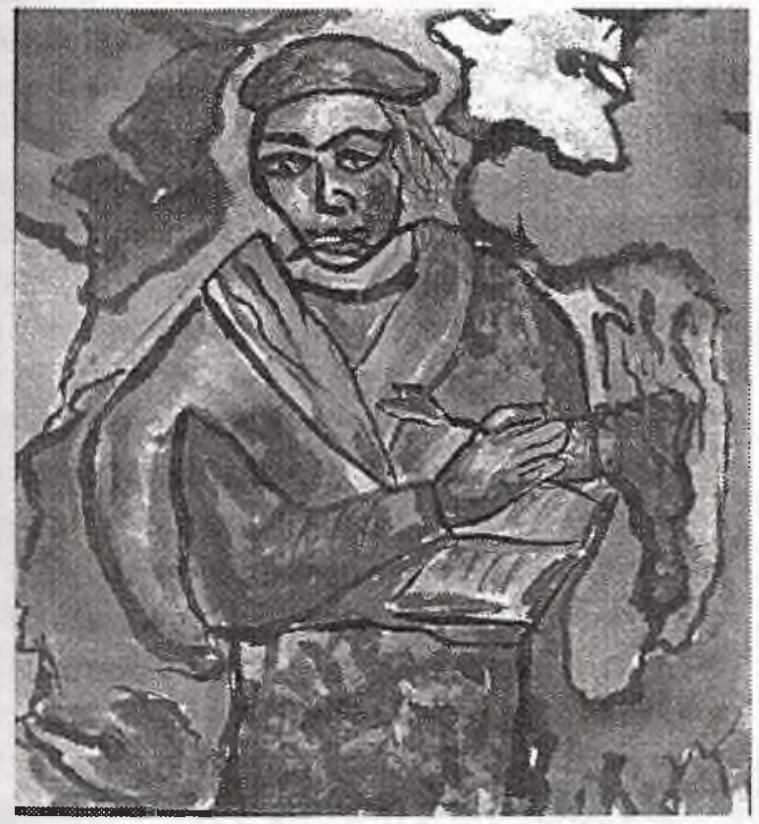

\section{CONTRASTE ENTRE LAS TEORÍAS DEL APRENDIZAJE DE PIAGET Y VYGOSTKY}

Valiosísimo aporte hizo Piaget a la psicología del aprendizaje; quizá lo más significativo en el campo de las ciencias pedagógicas en los últimos siglos. Según él, el aprendizaje no es un mero almacenamiento memorístico de datos trasmitidos por el mundo circundante (padres, maestros, compañeros): es toda una reelaboración por parte de su mente hasta lograr un ajuste con los conocimientos anteriormente asimilados, y que se traduce en lo

Aproximarnos periódicamente a la filosofía del aprendizaje es siempre saludable para los que revivimos cotidianamente la alegría de enseñar: es recuperar el entusiasmo por esta hermosa actividad, con la reflexión sobre los objetivos del quehacer pedagógico: es quitar de la piel las huellas de los rasguños que nos deja el diario roce con alumnos, colegas y directivos, mediante el lenitivo refrescante de los nuevos enfoques; es cerrar los ojos a las intranscendentes y desgastadoras pequeñas tareas diarias para abrirlos a los verdaderos horizontes y recuperar la dimensión de nuestra función en la comunidad. que él denominó "equilibrio". Cada nuevo conocimiento pone en crisis ese equilibrio anteriormente alcanzado hasta que una nueva organización o estructura reemplaza la anterior para devolver el equilibrio.

Sin embargo, Piaget atribuye al proceso cognitivo un carácter interno e individual: el conocimiento se produce en la interacción sujeto-objeto: la interacción con el maestro y con sus compañeros se da, según él, en un segundo momento o etapa del conocimiento. Este planteamiento ha sido clasificado "inside-out" ( de adentro hacia afuera).

- Lic. Filosofía y Ciencias Religiosas, Esp. Filosofía Colombiana, Aspirante al Mag. en Filosofía Latinoamericana, Profesor USCO. Dpto. de Artes 
El psicólogo ruso Vygostky (heredero de la corriente socialista del realismo pedagógico soviético) plantea en cambio, con su ley de doble formación, una profunda modificación al proceso del conocimiento: según él, todo nuevo desarrollo en el proceso cognoscitivo es primeramente de carácter interpersonal o social y sólo en un segundo momento se convierte en adquisición individual o intrapersonal. Este planteamiento ha sido catalogado como "outside-in" (de a fuera hacia adentro). Su tesis acerca de la zona de desarrollo próximo termina por convencernos de que cualquier nuevo conocimiento parte de la iniciativa del adulto, el cual va llevando al niño gradualmente a nuevas experiencias de aprendizaje a través de una "intervención eficaz". La regla de contingencia empero, nos hace caer en cuenta de que no se trata de un proceso mecánico en el que necesariamente, a cada acción del adulto haya de corresponder un resultado de aprendizaje, pero sí establece límites mínimo y máximo en los que éste puede darse como respuesta a aquélla.

Investigaciones posteriores como las de Hickmann y Wertsch, sobre la interacción madre-hijo y teorías como la de Bruner sobre la adquisición del lenguaje en el niño, confirmaron y complementaron la tesis de Vygostky, cuyas consecuencias sobre el acto pedagógico devuelven al maestro la función de iniciativa en el proceso de enseñanza.

\section{CARACTERÍSTICA PECULIAR DEL ACTO EDUCATIVO}

Se ha realizado, pues, un gran esfuerzo por parte de los actuales teóricos del aprendizaje para ubicar equiliz:adamente la esencia del acto educativo en la interacción de profesor y alumno. reconociendo la imprescindible actividad autoestructurante de su conocimiento por parte de éste último, a la vez que la innegable influencia del primero como planificador del proceso de aprendizaje a través de su "decisión de enseñar".

Subsiste sin embargo la antigua postura pedagógica que Freire denominó "educación bancaria", en la que el ryapel protagónico se concede al maestro, mientras al alumno se atribuye una función meramente pasiva y/o receptiva. Curioso, por decir lo menos, que sea en el nivel superior de la educación (la Universidad) donde prevalece el sistema expositivo de enseñanza: los otros dos niveles (primaria y secundaria) llevan varias décadas tratando de actualizarse, dando cada vez mayor importancia y participación a la actividad el alumno en el proceso. La Universidad pareciera pretender sentar la tesis de que esa actividad no se requiere para el verdadero aprendizaje adulto, descalificando entonces los avances y descubrimientos de la psicología.

Como reacción, un gran grupo de pensadores (psicólogos, pedadogos) ha abrazado fervientemente la tesis del papel protagónico del alumno en el proceso de construcción de su propio conocimiento, llegando a desconocer la influencia del maestro o relegándolo a un lugar muy secundario. La hiperbólica afirmación piagetiana de que transmitir un conocimiento es privar al alumno de la oportunidad de descubrirlo es acogida literalmente. En este orden de ideas algunos han llegado a pensar que solo existe aprendizaje pero no enseñanza: mantener hoy el antiguo término de "proceso enseñanza-aprendizaje" es considerado anticuado: lo "in" ahora es hablar sólo de aprendizaje. Curiosan:ente en todo el decreto 1860 no aparece ni una sola vez la palabra "enseñanza" en sus 8 capítulos y 67 artículos y esto no es casual. 
en tratándose del marco legal de todo el proceso de la educación de un país.

No. Ubiquémonos en el justo medio. La esencia del acto pedagógico radica en la interacción profesor alumno. Esto significa que, si bien el alumno solo habrá aprendido cuando haya reelaborado y hecho suyo el conocimiento, este proceso está precedido de la acción del profesor como facilitador y planificador de las condiciones en que esa actividad del alumno se posibilite. Recupera así el maestro su papel en la educación y se lo podrá responsabilizar de cumplir o incumplir su función (sin desconocer el carácter transitivo y transitorio de su acción). Pero aún más: sólo así adquiere sentido hablar de educación como acto intencional o voluntario que se propone sacar (Educere) al alumno de una condición para llevarlo (Ducere) a otra: lo contrario sería ubicar la educación en el terreno de lo exclusivamente espontáneo, aleatorio o lúdico e intranscendente.

La investigación en la práctica docente debe dirigirse entonces fundamentalmente a:

* Identificar pautas y secuencias interactivas que favorezcan la actividad autoestructurante (o de construcción) del conocimiento por parte del alumno.

* Mostrar los mecanismos con los cuales la interacción maestro-alumno incide en dicha actividad autoestructurante (aprendizaje).

\section{CULTURA Y PRÁCTICA DOCENTE}

Desafortunadamente, en nuestro medio se manejan conceptos de cultura, o muy elementales (desde la buenas maneras hasta la erudición o versación específica $y / o$ general) $o$ demasiado teóricos (vestigios del pasado, formas de relacinamiento del hombre con la naturaleza y sus semejantes, cultivo de las artes). Pero, por sobre todo, un concepto estático que supone que la cultura es un acervo histórico que se elaboró en el pasado y debe mantenerse inmodificado para trasmitirlo fielmente a las próximas generaciones. Nos cuesta trabajo admitir su carácter dinámico y evolutivo y esto trae como consecuencia que aún los que trabajamos con la cultura no nos sintamos creadores ni hacedores de la misma sino sus meros arqueólogos que se esfuerzan por desenterrarla para entregarla o mostrarla.

Por eso nunca se encuadró el proceso educativo en el marco de la cultura local o nacional: la educación parecía basarse en la ciencia cuya ubicación ordinaria era el libro, el maestro o la biblioteca; la cultura parecía ocuparse más bien del arte y del folklore, de las creencias y de las tradiciones y su lugar predilecto era la tradición oral. La una era regulada e impartida desde un ministerio y unas instituciones bien concretas (univer- 
sidades, escuelas y colegios); la otra era apoyada a través de organismos de "inferior categoría": los institutos de cultura.

La incorporación del concepto de cultura en la práctica docente implica primeramente repensar la escuela como proyecto cultural específico $y$, por lo tanto, perteneciente a la cultura nacional: la ciencia forma parte de la cultura pero ésta desborda los límites de la ciencia concebida en forma tradicional. En segundo lugar supone la toma de conciencia del doble carácter de la cultura: la académica que transmite conocimientos. competencias y habilidades para consumo interno de la misma institución escolar y la experiencia proveniente del contacto espontáneo y cotidiano del individuo con su grupo (fami liar, social, etc.) y suministra competencias. significados, creencias, etc., que él aplica y utiliza en su diario vivir. En tercer lugar convertir la escuela en ese espacio de intercambio y negociación entre las dos modalidades de cultura: la primera, convertida en herramienta intelectual que permita al individuo replantear su cultura experiencial sobre sus bases más sólidas: en una palabra, poner la cultura al servicio de la vida en lugar de continuar sacrificando al niño y a la persona en el cruento altar de la cultura.

\section{EL AULA COMO ESPACIO DE DIÁLOGO}

Audaz y riesgosa pero esperanzadora y desafiante, la propuesta pedagógica de Vygotsky y Bruner supone un replanteamiento, no sólo del acto educativo, sino hasta de los fundamentos epistemológicos de este proceso.
Delegar en primera instancia la etapa inicial del proceso (suministro de información) a los medios masivos de comunicación, los cuales disponen de mejores recursos que la escuela para esa tarea y amplían cada día más la cultura experiencial del alumno.

Partir de los preconceptos que sobre las disciplinas específicas traiga el alumno (cultura experiencial), permitiéndole exponerlos y compartirlos con su grupo. Al escuchar los conceptos y explicaciones provenientes de la disciplina respectiva expuestos por el profesor (cultura académica) debe permitírsele, por una parte que reinterprete y por otra parte, que ponga en evidencia la deficiencia de sus preconceptos provenientes del saber vulgar.

Se logra así descargar al proceso educativo de la etapa informativa para que enfatice en la etapa orientadora (crítica de valores destilados en la información de los medios de comunicación), integradora (dar sentido, organización y sistemacidad a la información) y práctica (desarrollo de actitudes).

El objetivo se desplaza entonces de los contenidos de la cultura académica a la "reconstrucción crítica del conocimiento vulgar" y ello exige del maestro una nueva actitud: asumir su papel de facilitador de contextos de comprensión, (partir de los conocimientos, intereses y preocupaciones del alumno) y mantener las posibilidades de negociación (de sentido, de aceptación, de exigencia), en lugar de recurrir a la imposición de sus conocimientos, competencias o decisiones.

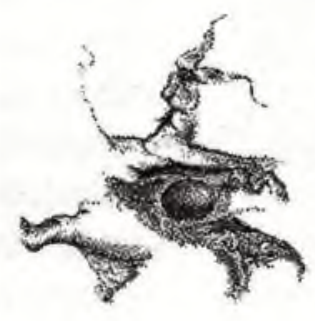




\section{CONCLUSIÓN}

Recuperemos las ideas más importantes expuestas en estas cuatro reflexiones.

* El momento más importante del acto educativo es el de la interacción del profesor y el alumno.

* El aprendizaje es en primera instancia un proceso interpersonal y social y luego deviene en intrapersonal o individual.

* La enseñanza es un proceso de andamiaje y apoyo para la actividad autoestructuran te del conocimiento por parte del alumno.

* $\quad$ El aprendizaje debe partir de espacios de diálogo compartido entre la cultura experiencial del alumno y la cultura académica del maestro.

* La cultura es un conjunto de representaciones individuales y colectivas que dan sentido a los intercambios entre los miembros de una comunidad.

* Los medios de comunicación están sustituyendo a la escuela en la función de transmisión de información.

* El aprendizaje debe partir de la cultura experiencial o saber vulgar del alumno y mediante las herramientas intelectuales de la cultura académica, permitir que el alumno reconstruya la cultura adulta.

* La escuela es un contexto artificial: los conocimientos se perciben en función de la evaluación.

* Hay que recontextualizar la escuela: crear una gran comunidad democrática de aprendizaje.

* E implicar al alumno en actividades relevantes para él y significativas para su comunidad: inmersión en la cultura, vivencia de la cultura.

\section{BIBLIOGRAFÍA}

1. COLL SALVADOR, César. Acción, interacción y construcción del conocimiento en situaciones educativas. Ed. Laia - Barcelona - 1987.

2. BRUNER, Jerónimo. Desarrollo Cognitivo y Educación. Ed. Morata - Madrid 1988.

3. BRUNER, Jerónimo. El Proceso Educativo. Ed. Paidós - Buenos Aires - 1973.

4. MARDONES, J. M. Filosofía de la Ciencias Humanas y Sociales. Ed. Antropos Barcelona - 1992.

5. PEREZ GOMEZ, Angel. Comprender y transformar la enseñanza. Ed. MorataMadrid - 2a. Edición - 1993.

6. PIAGET, Jean. Psicología y Pedagogía. Ed. Ariel - Barcelona - 1972.

7. VYGOTSKY, L. S. El Desarrollo de los Procesos Psicológicos Superiores. Ed. Grijalbo - Barcelona. 1989. 